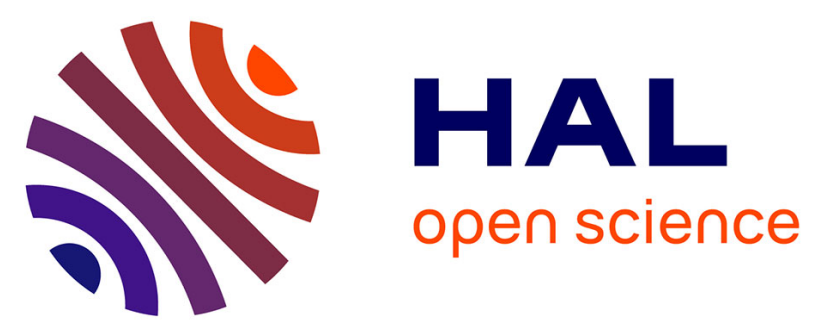

\title{
The influence of biosurfactant adsorption on the physicochemical behaviour of carbon steel surfaces using contact angle measurements and X-ray photoelectron spectroscopy
}

\author{
V. Shubina, L. Gaillet, S. Ababou-Girard, V. Gaudefroy, T. Chaussadent, F. \\ Farcas, T. Meylheuc, C. Dagbert, Jordi Creus
}

\section{To cite this version:}

V. Shubina, L. Gaillet, S. Ababou-Girard, V. Gaudefroy, T. Chaussadent, et al.. The influence of biosurfactant adsorption on the physicochemical behaviour of carbon steel surfaces using contact angle measurements and X-ray photoelectron spectroscopy. Applied Surface Science, 2015, 351, pp.11741183. 10.1016/j.apsusc.2015.06.057 . hal-01168328

HAL Id: hal-01168328

https://hal-univ-rennes1.archives-ouvertes.fr/hal-01168328

Submitted on 19 Nov 2015

HAL is a multi-disciplinary open access archive for the deposit and dissemination of scientific research documents, whether they are published or not. The documents may come from teaching and research institutions in France or abroad, or from public or private research centers.
L'archive ouverte pluridisciplinaire HAL, est destinée au dépôt et à la diffusion de documents scientifiques de niveau recherche, publiés ou non, émanant des établissements d'enseignement et de recherche français ou étrangers, des laboratoires publics ou privés. 


\title{
The influence of biosurfactant adsorption on the physicochemical behaviour of carbon steel surfaces using contact angle measurements and $\mathrm{X}$-ray photoelectron spectroscopy
}

\author{
V.Shubina $^{a}$, L.Gaillet ${ }^{a}$, S.Ababou-Girard ${ }^{b}$, V.Gaudefroy ${ }^{a}$, T.Chaussadent ${ }^{c}$,

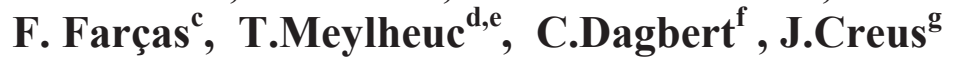 \\ ${ }^{a}$ LUNAM Université, IFSTTAR, MAST, SMC, F-44340 Bouguenais, France \\ ${ }^{b}$ Institut de Physique de Rennes, Département Matériaux et Nanosciences, UMR \\ 6251 CNRS, Université Rennes 1, 35000 Rennes-Cedex, France \\ c Université Paris-Est, IFSTTAR, MAST, CPDM, F-77447 Marne-la-Vallée, \\ France \\ ${ }^{d}$ INRA, UMR1319 Micalis, F-78352 Jouy-en-Josas, France \\ e AgroParisTech, UMR Micalis, F-78352 Jouy-en-Josas, France \\ ${ }_{2}$ Chemin de la Grand'côte, 36270 Éguzon-Chantôme \\ ${ }^{g}$ LaSIE, UMR7356, Université de La Rochelle, Pôle Sciences et Technologie, \\ Bâtiment Marie Curie, Avenue Michel Crépeau, 17000, La Rochelle, France
}

\begin{abstract}
We investigated modifications to carbon steel surfaces due to the adsorption of a biosurfactant derived from Pseudomonas fluorescens bacteria cells using contact angle measurements (CAM) and X-ray photoelectron spectroscopy (XPS). After conditioning carbon steel in solutions with three different concentrations of biosurfactant molecules: $0.05,0.3$ and 1 g. $\mathrm{L}^{-1}$, the average thickness of the biosurfactant layer on the carbon steel specimens was $7.9 \pm 0.3,12.1 \pm 0.5$ and $16.4 \pm 0.7 \AA$, respectively. The biosurfactants changed the composition of both the $\mathrm{Fe}^{2+}$ and $\mathrm{Fe}^{3+}$ mixed-oxide layer and the outer layer, mostly composed of $\mathrm{Fe}^{3+}$ associated with magnetite. Contact angle measurements indicate decreased hydrophobic properties after the carbon steel was modified by biosurfactant. It was shown that the carbon steel surface free energy depends on the biosurfactant concentration, due to an acquisition of strong electron-donating properties.
\end{abstract}




\section{INTRODUCTION}

Many bacteria are able to produce amphipathic substances (also called "biosurfactants"), which are potentially interesting compounds for many fields of study, due to having both hydrophilic and hydrophobic moieties in the same molecule. This internal "opposition" allows them to exhibit surface active properties and favour aggregation at phase boundaries or interfaces. Their hydrophobic parts can be saturated/unsaturated hydrocarbon chains or fatty acids; while their hydrophilic parts are mainly composed of an acid, peptide or mono-, di-, or polysaccharides [1].

Interest in biosurfactants has been increasing in recent years, as they have advantages, compared with chemical surfactants, such as environmental compatibility, lower toxicity, higher biodegradability [2-3]. They have already numerous applications in different industrials fields: pharmaceutical and cosmetic industries, enhanced oil recovery and bioremediation [4]. Nevertheless, their large-scale application are limited by the high cost of production and by limited understanding of their interactions with different surfaces and with environment [4].

Different kinds of bacteria synthesise a wide range of compounds such as glycolipids (Pseudomonas aeruginosa, Rhodococcus erythropolis [5-6]) phospholipids (Corynebacterium lepus [7]), fatty acids (Nocardia erythropolis [8]), polymeric surfactants (Acinetobacter calcoaceticus [9]) and lipopeptides (Bacillus subtilis, Pseudomonas fluorescens, Serratia marcescens [10-12]). Lipopeptides class of biosurfactants are of interest because of their wide range of biological activities like antibiotic, antifungal, antiviral and antitumour [1314]. Lipopeptides are stable at high temperatures, over a large range of $\mathrm{pH}$ and at high salt concentrations [14].

Meylheuc et al. [15] ascertained that lipopeptide biosurfactants derived from Pseudomonas fluorescens improve antibacterial properties and repulse the 
adhesion of pathogenic Listeria monocytogenes. This kind of biosurfactant barrier coating on the stainless steel surface was studied using CAM, AFM, XPS and PM-IRRAS [16]. As a matter of fact, AFM observations enabled to say that probably the biosurfactant layer covered the surface with patches. Dagbert et al. $[17,18]$ found a difference in the corrosion behaviour of a stainless steel surface when modified by biosurfactant obtained from gram-negative bacterium Pseudomonas fluorescens in $0.15 \mathrm{M} \mathrm{NaCl}$.

The corrosion behaviour of carbon steel was also studied in simulated concretepore solutions contaminated by chlorides $(0.5 \mathrm{M} \mathrm{NaCl})$ with and without adding lipopeptides from Ps. fluorescens [19-21]. Polarization curves and electrochemical impedance spectroscopy demonstrated that these biosurfactants can be regarded as good inhibitors of steel corrosion in the presence of chloride ions. Despite these extensive studies [15-21], many aspects of layer composition and thickness are still poorly understood. The interesting electrochemical results encouraged the authors to further investigate the process occurring between the carbon-steel surface and the biomolecules used in previous studies [21].

Therefore, in the present work contact angle measurements (CAM) and XPS analysis were conducted, to make a more precise assessment of the surface modification of low carbon steel by biosurfactants. Three concentrations of biomolecules, corresponding to three different states of molecules in the

solution, were used in this study, among them the concentration of 1 g.L $\mathrm{L}^{-1}$ that was reported as a promising one in [21]. In addition, we attempted to estimate the biosurfactant layer thickness from XPS data. Complementary FTIR analysis was used to confirm the possible lipopeptide nature of $P$. fluorescens biosurfactants provided earlier in the literature (viscosin, surfactin, viscosinamide [22]).

\section{MATERIALS AND METHODS}




\subsection{Steel substrates and preparation}

The carbon steel for this study was kindly provided by PLBArmatures (AlliansSnaam, Carquefou, France). The chemical composition of the carbon steel is presented in

Table 1. Figure 1 shows the ferritic-pearlitic microstructure deduced from Nital etching of the low carbon steel. We observe that the pearlite grain density is very low compared to the ferritic grain density.

Table 1. Chemical composition of carbon steel (wt. \% of main elements)

\begin{tabular}{|l|l|l|l|l|l|}
\hline $\mathrm{C}$ & $\mathrm{S}$ & $\mathrm{P}$ & $\mathrm{N}$ & $\mathrm{Cu}$ & $\mathrm{Fe}$ \\
\hline 0.24 & 0.055 & 0.055 & 0.014 & 0.85 & balance \\
\hline
\end{tabular}

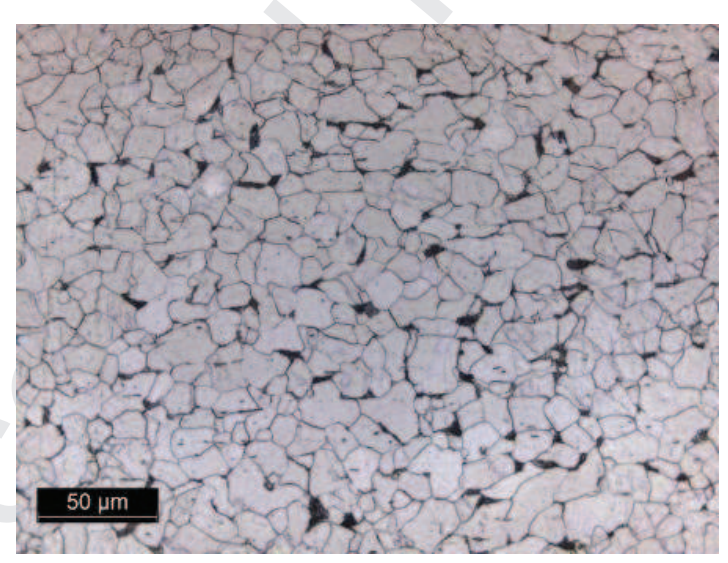

Figure 1. Carbon steel microstructure: the light ferrite region and the dark pearlite regions.

The samples were disk cut from rebars of two different diameters: $0.6 \mathrm{~cm}$ (for XPS) and $2 \mathrm{~cm}$ (for CAM). The samples were embedded in epoxy resin with an exposed surface area of $0.28 \mathrm{~cm}^{2}$ and $3.14 \mathrm{~cm}^{2}$, respectively. The specimens were mechanically polished with $\mathrm{SiC}$ emery paper down to grade 1200 , then with $6 \mu \mathrm{m}, 3 \mu \mathrm{m}$ and $1 \mu \mathrm{m}$ diamond paste. Then they were degreased in ethanol, and three times in distilled water, and finally dried under an air flow. 


\subsection{Biosurfactant production}

The biosurfactant was kindly provided by Thierry Meylheuc and was prepared as described previously in reference [15]. Briefly, isolated bacteria were kept frozen at $-80^{\circ} \mathrm{C}$ in cryotubes before production. Petri dishes of King B Agar (KBA, Merck) were used for bacteria growth. Each KBA plate (about 80 plates to $150 \mathrm{~mL}$ of $\mathrm{BS}$ ) was inoculated with cryotube suspension for dense coverage of the agar surface. Inoculated plates were then incubated at $20-22^{\circ} \mathrm{C}$. After 4 days' incubation, the KBA surfaces were scraped, then the cells were suspended in $150 \mathrm{~mL}$ of sterile deionized water and shaken strongly for $3 \mathrm{~min}$ (Vortex, Bioblock, France). The supernatant containing the biosurfactant was separated from the cells by centrifuging for $30 \mathrm{~min}$ at $18,000 \mathrm{~g}$. The supernatant was carefully recovered then sterilized $\left(121^{\circ} \mathrm{C}, 20 \mathrm{~min}\right)$ and stored at $4^{\circ} \mathrm{C}$.

\subsection{Fourier transform infrared spectroscopy analysis}

Fourier transform infrared spectroscopy (FTIR) is based on how the test substrate absorbs infrared radiation. The result of FTIR analysis is a spectrum that is like a fingerprint of a sample with absorption peaks that correspond to the vibration frequencies between the bonds of the atoms making up the material. The FTIR spectra in transmission mode were obtained by analysing an evaporated biosurfactant sample on a potassium bromide $(\mathrm{KBr})$ pellet. The resulting pellet was analysed by transmission with a Nicolet 380 spectrometer between $4000 \mathrm{~cm}^{-1}$ and $400 \mathrm{~cm}^{-1}$ with a scan number of 32 and a resolution of 2 $\mathrm{cm}^{-1}$.

\subsection{Conditioning of carbon steel surfaces}

Before conditioning, the surfaces were cleaned with deionized water at $20^{\circ} \mathrm{C}$. Conditioned surfaces were obtained by immersion of carbon steel coupons in four solutions with biomolecules concentrations of 1 g.L $\mathrm{L}^{-1}$ (BS-1), 0.3 g.L ${ }^{-1}$ (BS- 
0.3), 0.05 g.L $\mathrm{L}^{-1}$ (BS-0.05) and 0 g.L $\mathrm{L}^{-1}$ (Blank sample) for $20 \mathrm{~h}$ at $20^{\circ} \mathrm{C}$ (the necessary time was determined in $[15,16])$. Non-adsorbed compounds were then removed from the carbon steel surface by being gently soaked in deionized water and dried on laminar air flow. A carbon steel sample not subjected to any treatment (Blank sample) was also studied.

\subsection{Surface tension and contact angle measurements}

The aqueous BS solutions were prepared using double distilled water (Millipore Q, $12.6 \mathrm{~m} \Omega . \mathrm{cm})$. The water was additionally tested $(\gamma \mathrm{LV}=$ $72.28 \mathrm{mN} . \mathrm{m}^{-1}$ ) by surface tension measurements before the solutions containing the BS were prepared. The equilibrium surface tension $(\gamma \mathrm{LV})$ of all the solutions was measured by the Drop Shape Analyser DSA100 (KRUSS, Gmbh) according to the pendant drop method. The sterile syringes (NE 43, KRUSS, Gmbh) were used for each new measurement. The standard deviation depending on the surfactant concentration ranges from \pm 0.10 to $\pm 0.65 \mathrm{mN} . \mathrm{m}^{-1}$. The test chamber temperature was controlled using two thermostatic water baths. All the experiments were carried out at $20^{\circ} \mathrm{C}$. For each concentration, more than 15 successive measurements were carried out.

Contact angle measurements for four different liquids (distilled water, diiodomethane, glycerol and ethylene glycol) were carried out at room temperature. The sessile drop method for the contact angle determination was used through deposition of liquid drops on solid surfaces with a micrometric syringe and controlled by means of a camera. The contact angles were determined from the droplet image using the tangent method. At least contact angles of 5 droplets were measured for each solvent on three independently conditioned surfaces. The final values were averaged on at least two different locations on the surface.

\subsection{XPS measurements}


XPS spectra were obtained on a Kratos Nova equipped with a monochromated Al k $\alpha$ X-Ray source $(\mathrm{h} v=1486.6 \mathrm{eV})$. Analysis was carried out using an accelerating voltage of $15 \mathrm{kV}$ and an emission current of $10 \mathrm{~mA}$. All the survey spectra were performed at a pass energy of $160 \mathrm{eV}$ to identify all the elements present in the analysed specimens. Chamber pressure during analysis was $7 \times 10^{-8}$ Torr. Preliminary tests on carbon steel conditioned in biosurfactants (examples of spectrum for BS-1 see in Figure 5, part 3.3.1) have shown charge effects on photoemission (obviously due to an insulating film on the surface) which therefore requires the use of the neutralizer during all experiments. To check the reproducibility of the results, survey spectra and high resolution spectra for $\mathrm{Fe}$ $2 \mathrm{p}, \mathrm{C} 1 \mathrm{~s}, \mathrm{O} 2 \mathrm{~s}$ and N1s were recorded on two different locations on each specimen. Moreover, two independently prepared specimens for each concentration of interest were studied. Binding energies were determined by reference to the $\mathrm{C} 1 \mathrm{~s}$ component (recorded from HOPG sample) set at $285.0 \mathrm{eV}$. Curve fitting of high resolution XPS spectra and Semi-Quantification Analysis was performed using CasaXPS data software.

\section{RESULTS AND DISCUSSION}

\subsection{Characterization of isolated BS}

\subsubsection{FTIR analysis}

The FTIR spectrum illustrated in Figure 2 is a signature of the BS. 


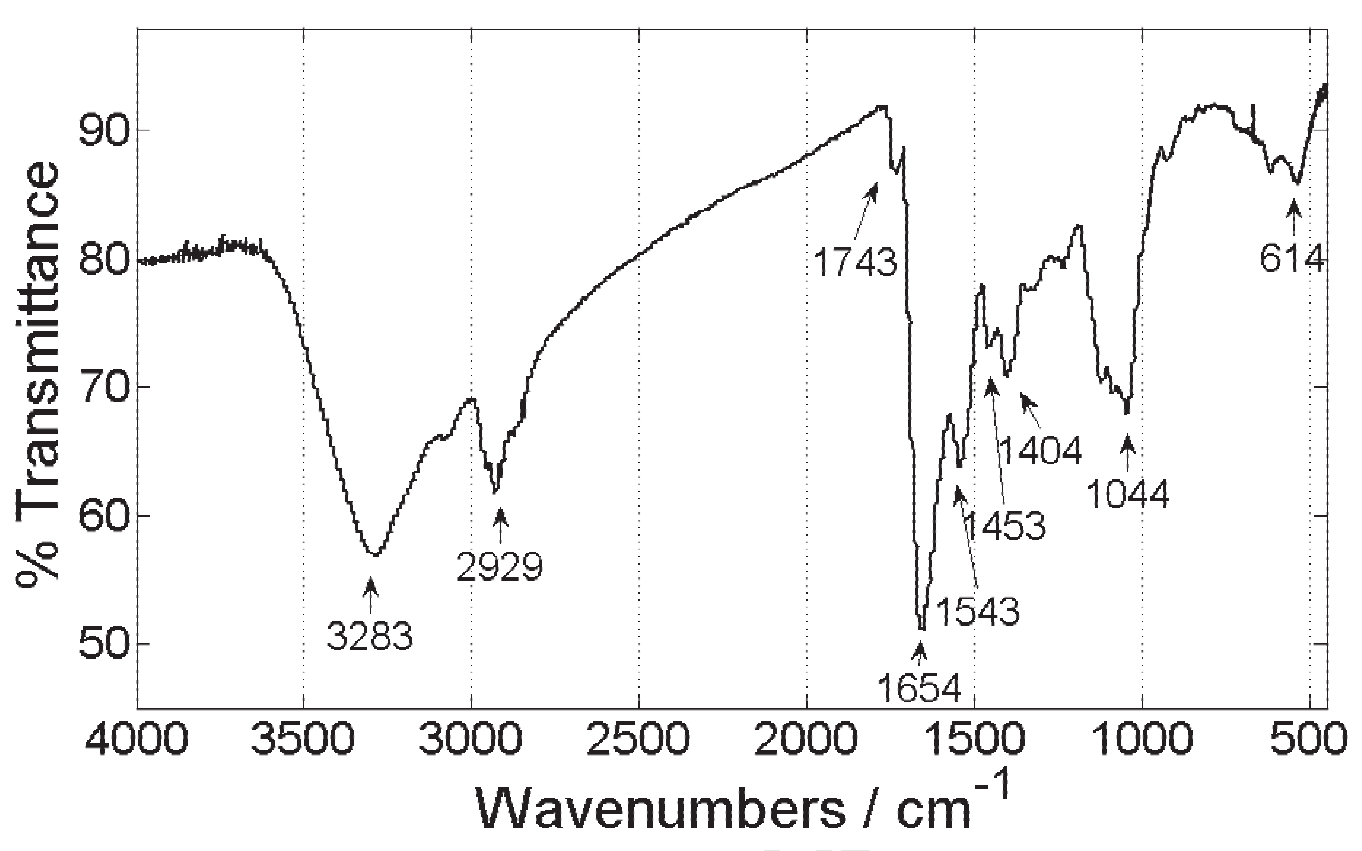

Figure 2. FTIR spectrum of the dried BS

The main FTIR absorption peaks attributions reported in Table 2 highlight the presence of amide bands. They are in good accordance with the composition of peptide compounds, which represent the hydrophobic part of biosurfactants. The presence of polysaccharides is due to the use of the non-purified biosurfactant (polysaccharides are substances secreted by bacteria to organize them into biofilms) [22]. The carbon was also stored as lipids: $\mathrm{CH}_{2}$ stretching in the 2850$2950 \mathrm{~cm}^{-1}$ region and $\mathrm{C}=\mathrm{O}$ stretching at $1743 \mathrm{~cm}^{-1}$.

These absorptions confirm the lipopeptide nature of the biosurfactant $[23,24]$ and correlate positively with the XPS analysis.

Table 2. Attribution of the main BS FTIR absorption peaks [22-24].

\begin{tabular}{|c|c|}
\hline $\begin{array}{c}\text { Wavenumber } \\
\left(\mathrm{cm}^{-1}\right)\end{array}$ & Chemical functions \\
\hline 3283 (broad) & v OH (hydroxyl) \\
\hline $2850-2950$ & $v \mathbf{C H}_{3}, v \mathbf{C H}_{2}, v \mathbf{C H}($ aliphatic chains) \\
\hline 1743 & $\nu \mathbf{C}=\mathbf{O}$ \\
\hline 1654 & $\nu \mathrm{N}-\mathrm{C}=\mathrm{O}$ (amide) \\
\hline
\end{tabular}




\begin{tabular}{|l|l|}
\hline 1543 & $\delta \mathrm{N}-\mathrm{H}$ combined with $v \mathrm{C}-\mathrm{N}$ (amide) \\
\hline 1453 & $\delta \mathrm{CH}_{2}$ \\
\hline 1404 & $\delta \mathrm{CH}_{3}$ \\
\hline 1044 & polysaccharide or polysaccharide-like substances \\
\hline$v:$ Streching vibration \\
$\delta:$ Deformation vibration
\end{tabular}

\subsubsection{Surface tension isotherm}

The biosurfactant surface tension plot is presented in Figure 3. It is clear that in the presence of biosurfactant, the water's surface tension dropped linearly with increasing biosurfactant concentration until the biosurfactant critical micelle concentration (CMC) of approximately 0.6 g.L.-1 was reached. The shape of this surface tension isotherm depends on two factors: (i) density and (ii) orientation of biomolecules at the interface layer. 


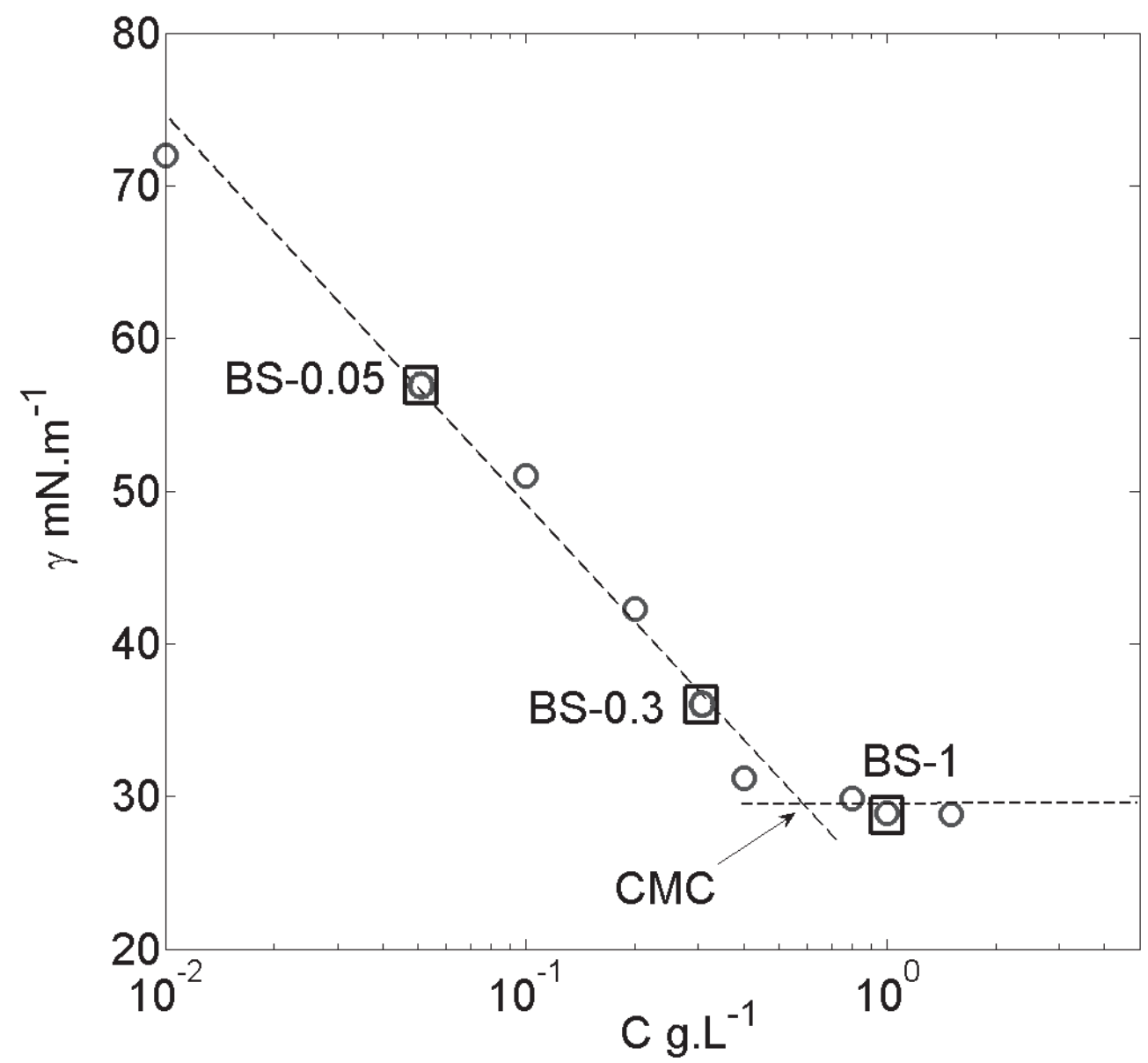

Figure 3. Surface tension measurements $(y)$ for aqueous biosurfactant solutions versus logarithm of $\mathrm{BS}$ concentration $(\mathrm{C})$.

The surface tension of $30.01 \mathrm{mN} \cdot \mathrm{m}^{-1}$ is in good accordance with the data of previous studies on lipopeptides reported in literature [25]. The surface tension curve can also provide information on the critical micellar concentration point (CMC). Above the CMC point, surfactant molecules have a tendency to selforganize into micelles or aggregates in the solution and surface tension values do not vary significantly. The literature data about a CMC point for lipopeptides was mainly obtained from surface tension values changing as a function of their concentrations and is in the range $1 \times 10^{-4}$ g. $\mathrm{L}^{-1}-2 \times 10^{-2}$ g.L $\mathrm{L}^{-1}[\mathbf{2 6}]$. However, our $\mathrm{CMC}$ value was higher than those reported. This difference may be due either to 
the use of non-purified biosurfactant or to the fact that a wide variety of cyclic lipopeptides (CLs) are produced by bacteria. It was reported that the BSs produced by Pseudomonas fluorescens can be a mixture of 4-5 homologues [2728].

After exploring the biosurfactants surface tension, three points (indicated in Figure 3), corresponding to the three different configurations of biomolecules in aqueous solution were selected:

- The point designated subsequently as BS-0.05 represents a zone with slight surface tension variation compared with that of water $\left(72.28 \mathrm{mN} \cdot \mathrm{m}^{-1}\right)$ at low BS concentrations;

- The point denoted as BS-0.3 represents a zone with a sharp decrease in surface tension when biosurfactant molecules are added;

- The point called BS-1, located after the CMC and corresponding to the zone of micellization of biosurfactant molecules, i.e. the surface and volume of solution is fully charged with surfactant molecules. The plateau of this zone in Figure 3 indicates that no further change in surface tension was produced.

A sample conditioned in sterile deionized water without addition of biosurfactant molecules was used as Blank with further designation BS-0.

\subsection{Contact angle measurements (CAM) and surface free energy calculations}

The results of contact angle measurements are shown in Table A-1 (Appendix). For sample BS-0 the measurements were not carried out due to zones of localized corrosion (pitting) on the surface, which may have affected the spreadability of drops and distort the measurements. 
As can be seen from Table A-1 (Appendix), the most remarkable changes were the increase of spreadability of water droplets, i.e. the decrease of contact angle values of water from $76.7^{\circ}$ (Blank) to $28.9^{\circ}, 0^{\circ}$ and $0^{\circ}$, with BS-0.05, BS-0.3 and $\mathrm{BS}-1$, respectively. Because of complete wetting of the surface for two samples (BS-0.3 and BS-1) we had difficulty in ascertaining the contact angles, so a value of $0^{\circ}$ was used. Moreover, regarding the change in water contact angle over time, presented in Figure 4 (curve b), for Blank and conditioned surfaces, we can assume a substantial increase of surface wetting properties. In other words, this data suggested that carbon steel surfaces had been modified by surface-active biomolecules, this effect having been already evidenced on stainless steel surface in [15].

Characteristically, these facts indicate of favourable adsorption of the test liquid on the surface [29].

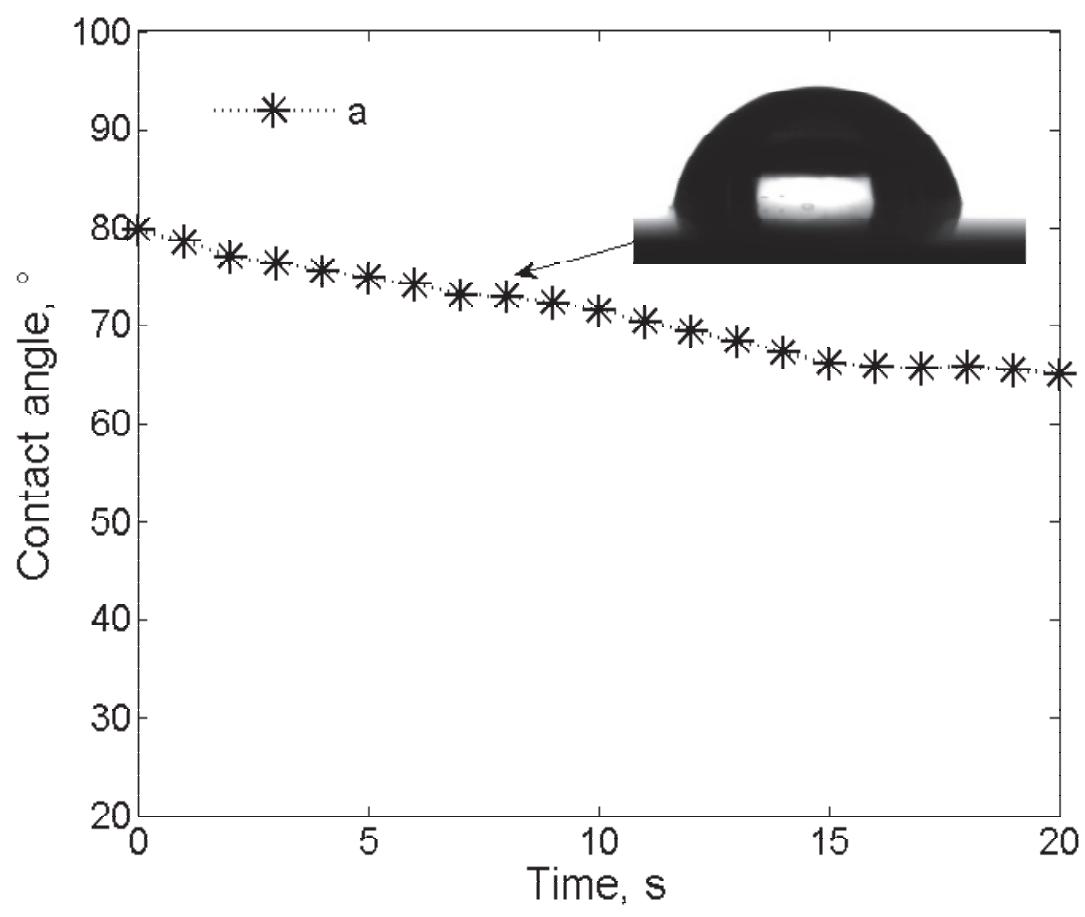






Figure 4. Evaluation of water contact angles over time on Blank (a) and conditioned (BS-1) samples (b).

The modification due to the adsorption of biomolecules is accompanied by a change of carbon steel surface tension. The surface tension of conditioned samples was calculated from a set of liquid/solid contact angles, developed by bringing four liquids (diiodomethane, ethylene glycol, glycerol and water) in contact with surfaces [30].

Owens/Wendt theory (also named the "harmonic method") was used to determine the surface free energy for our case. This approach considered the surface energy of a solid as a two-component model: a dispersive component (van der Waals and other non-specific interactions with applied liquid) and a polar component (dipole-dipole, dipole-induced dipole, hydrogen bonding and other site-specific interactions). The combination of the equations of Good and Young produces the Owens/Wendt theory: 


$$
\frac{\sigma_{L}(\cos \theta+1)}{2 \sqrt{\left(\sigma_{L}^{D}\right)}}=\sqrt{\sigma_{S}^{P}} \frac{\sqrt{\sigma_{L}^{P}}}{\sqrt{\sigma_{L}^{D}}}+\sqrt{\sigma_{S}^{D}} \quad(\mathrm{y}=\mathrm{mx}+\mathrm{b}),(\mathbf{E q . 1}) .
$$

Thus, the contact angle $(\theta)$ was measured using different liquids with known values of surface tension for the liquids and their polar and dispersive components (Table A-2 of Appendix). The surface free energy components of carbon steel samples can be obtained using (Eq. 1). The parameters listed in Table 3 were calculated from experimental data for liquid contact angles on unconditioned (Blank) or conditioned carbon steel (BS-0.05, BS-0.3, BS-1).

Table 3. Surface free energy components by Owens/Wendt theory.

\begin{tabular}{|c|c|c|c|}
\hline \multirow{2}{*}{ Sample } & \multicolumn{3}{|c|}{ Surface free energy components, (mN/m) } \\
\cline { 2 - 4 } & $\sigma_{S}^{D}$ & $\sigma_{S}^{P}$ & $\sigma_{S}$ \\
\hline Blank & $39.21 \pm 1.50$ & $5.90 \pm 1.20$ & $45.11 \pm 2.70$ \\
\hline BS-0.05 & $24.01 \pm 0.80$ & $31.26 \pm 1.30$ & $55.27 \pm 2.10$ \\
\hline BS-0.3 & $20.25 \pm 0.90$ & $43.56 \pm 2.00$ & $63.81 \pm 2.90$ \\
\hline BS-1 & $19.36 \pm 0.80$ & $43.56 \pm 2.00$ & $62.92 \pm 2.80$ \\
\hline
\end{tabular}

The total surface energy and components for the Blank sample are in good accordance with literature data $[31,32]$.

A comparison between the surface energy values in Table 3 shows that the carbon steel samples after conditioning demonstrated a significant increase in polar component from 5.90 to $43.56 \mathrm{mN} \cdot \mathrm{m}^{-1}$. Previously Rodrigues et al. [33] revealed that BSs reduce hydrophobic interactions, and new hydrophilic surface reach of electron-donating properties appears. In its turn, the electron-donating properties represent principally an increase in a basic component, which with 
acidic components gave in sum the polar component of surface energy [34]. The basic characteristic resulted from the presence of chemical groups such as $\mathrm{COO}^{-}$ or $\mathrm{HSO}_{3}{ }^{-}$on the conditioning surfaces [35]. Otherwise, strong surface hydrophilicity can be due to a well-organized surfactant layer, terminated by $\mathrm{COOH}$ or $\mathrm{COO}^{-}$groups and not a mixture of them, as was investigated by Vallée et al. [36]. After the conditioning in different biosurfactant concentrations $\left(0.05,0.3\right.$ and 1 g. $\left.\mathrm{L}^{-1}\right)$, the corrosion inhibition of carbon steel was observed, compared to sample BS-0 (conditioned in distilled water without addition of BS). Because BSs contain nitrogen, they can be considered to be hard bases and so they have good adsorption properties for metal surfaces [37]. Moreover, the FTIR analysis demonstrated a cyclic BS structure, which is often better for adsorption than an acyclic structure, as a ring leaves the nitrogen lone pair more exposed for donation, according Lewis acid-base theory [30]. In that way, chemical corrosion inhibitors based on amine compounds improve their corrosion inhibition properties.

In addition, a decrease of dispersive component from 39.21 to $19.36 \mathrm{mN} \cdot \mathrm{m}^{-1}$ was also established due to masking a surface. This is another proof of good adsorption of biosurfactant molecules.

CAM has allowed us to elucidate the adsorption of biosurfactant molecules as a function of concentration on the macro scale. It was shown that the higher the concentration (up to $1 \mathrm{~g} . \mathrm{L}^{-1}$ ), the higher carbon steel surface free energy will be, due to a surface modification. However, when the solution is near (BS-0.3) or above the CMC (BS-1), no significant increase of surface energy polar component was noticed. To confirm and study this in greater depth, a more sensitive physicochemical method, XPS analysis, was used.

\subsection{XPS analysis}


XPS analysis has been of key importance in the field of corrosion science for organic films of inhibitors [38] in different corrosion media. In this paper, XPS analysis was used to investigate the composition of the biosurfactant layer adsorbed on the carbon steel surface, and to evaluate the layer thickness for different BS concentrations: BS-0.03, BS- 0.5 and BS- 1 .

\subsubsection{Survey scan analysis}

We first recorded the survey scans of all the samples. Carbon steel surfaces of Blank, BS-0 and BS-1 samples are presented in Figure 5. Collected XPS survey spectra provide information about the presence of $\mathrm{C} 1 \mathrm{~s}$ at $298.0 \mathrm{eV}, \mathrm{N} 1 \mathrm{~s}$ at $400.0 \mathrm{eV}, \mathrm{O} 1 \mathrm{~s}$ at $530.9 \mathrm{eV}$ and all characteristic peaks of iron, with the main peak situated between 710.0 and $730.0 \mathrm{eV}$ with doublet structure $\mathrm{Fe} 2 \mathrm{p}_{3 / 2}$ and $\mathrm{Fe}$ $2 \mathrm{p}_{1 / 2}$. For all the spectra, we observed that the signals of $\mathrm{Fe}, \mathrm{O}$ and $\mathrm{C}$ are intensified compared to the other elements. Traces of other elements ( $\mathrm{Ca} 2 \mathrm{p}, \mathrm{P}$ $2 p)$ were found in small quantities for biosurfactant-conditioned samples, (acceptable values, caused by the presence of phosphate salts used for bacteria growth for biosurfactants production), and will not be discussed in this paper. 


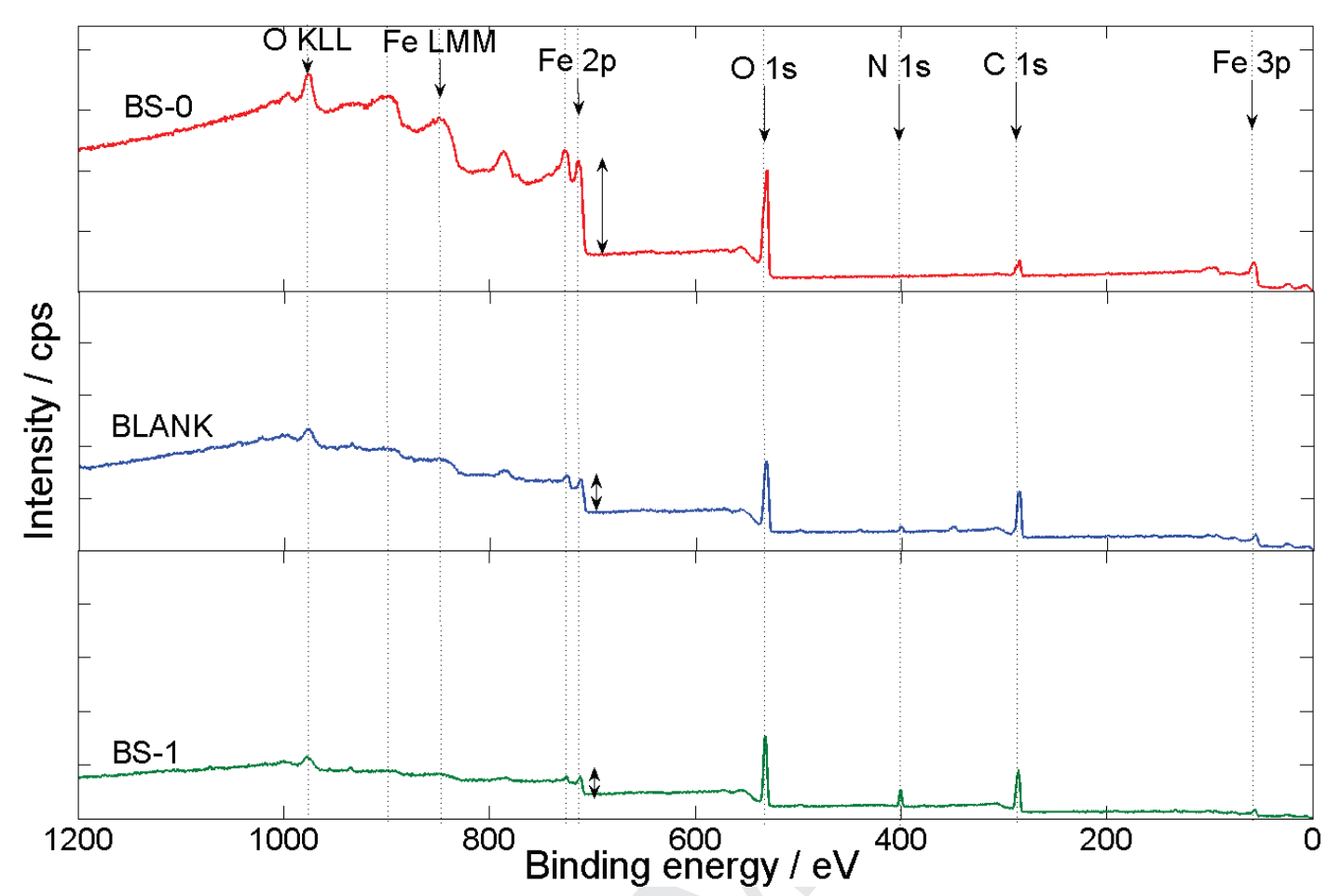

Figure 5. XPS survey spectra of carbon steel of Blank (blue line), BS-0 (red line) and BS-1 (green line) samples.

For the Blank sample, we obtained a typical survey scan for carbon steel [39]. This spectrum reflects the elements normally present in the composition of carbon steel, as it was provided from chemical analysis (see 2.1). Comparing with the spectrum of sample BS-1, we can clearly see the difference. All the peaks related to the iron signal are significantly decreased (Table A-3 of Appendix), indicating that a thin layer of biosurfactants was on the surface (detailed analysis will be presented later in $\mathbf{3 . 3 . 5}$ ).

Another feature for all biosurfactant-conditioned surfaces was the presence of a nitrogen peak. It can be attributed to a biosurfactant fingerprint on the carbon steel surface. 
For the BS-0 sample the surface is seen to be highly oxidized (corrosion products on the surface), and the substantial increase and slight shift of Fe $2 p$ peak can be seen.

We then studied the high resolution spectra for $\mathrm{C} 1 \mathrm{~s}, \mathrm{O} 1 \mathrm{~s}, \mathrm{~N} 1 \mathrm{~s}$ and $\mathrm{Fe} 2 \mathrm{p}$ to get a better understanding and more information about adsorbed biosurfactant molecules and the corrosion protection mechanism.

\subsubsection{Analysis of C 1s spectra}

The deconvoluted C 1s core level spectra for BS-0 (Blank) and BS-1 samples are presented in Figure $6(\mathbf{a}, \mathbf{b})$.






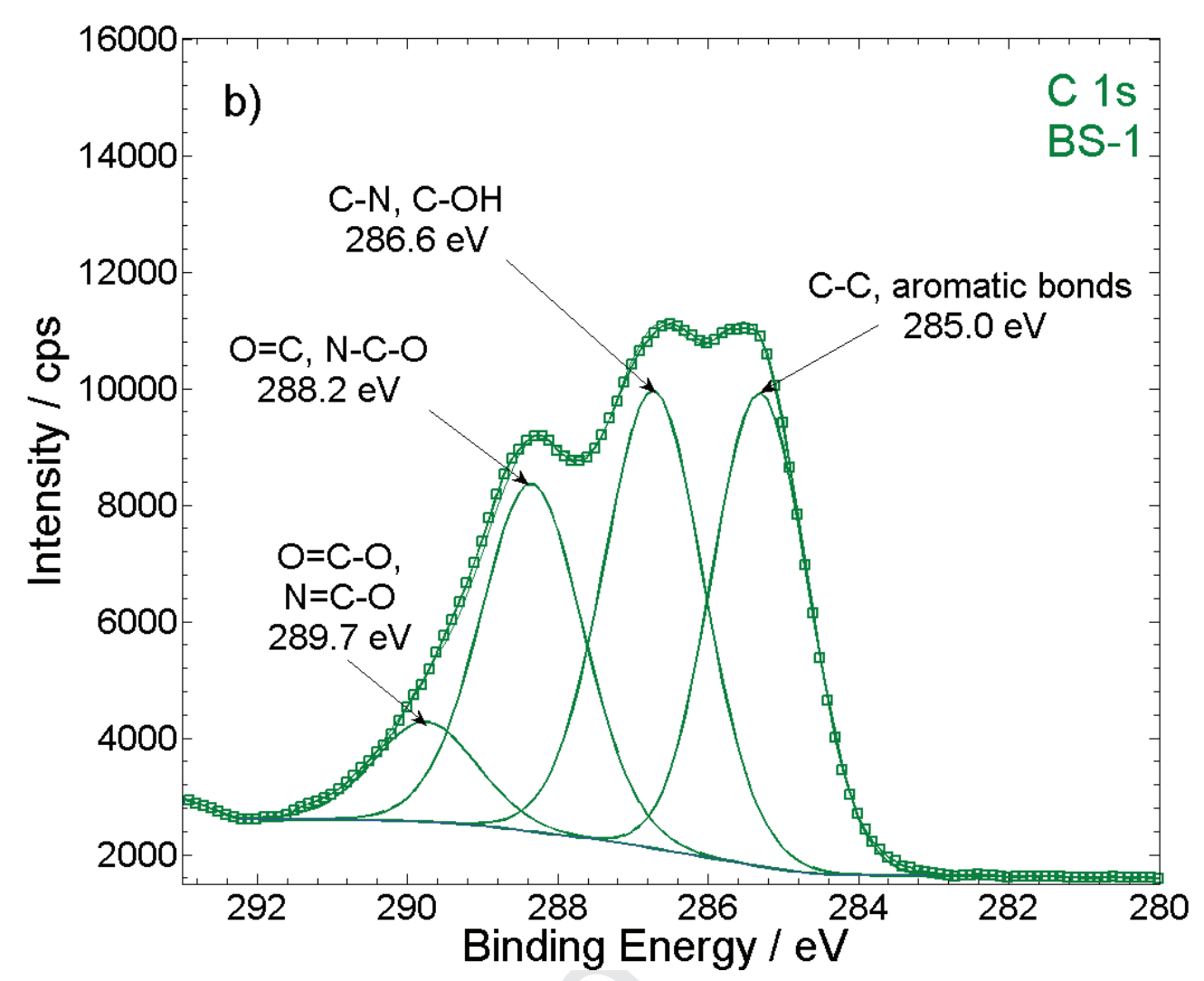

Figure 6. C 1s high resolution XPS spectra obtained for Blank sample (a) and BS-1 samples (b).

For the Blank sample, the largest contribution is attributed to the first peak of a carbon single bond with the other carbon or hydrogen located at approximately $285.0 \mathrm{eV}$. The second peak at $286.4 \mathrm{eV}$ is attributed to a carbon making a single bond with oxygen $(\mathrm{C}-\mathrm{O})$. This binding energy corresponds also to a carbon making a single bond with nitrogen $(\mathrm{C}-\mathrm{N})$, but we considered that that contribution was weak (see the $\mathrm{N} 1 \mathrm{~s}$ spectrum in Figure 8). The last component at $288.2 \mathrm{eV}$ is a small contribution and suggests creation of double carbon-oxygen bonds $(\mathrm{O}=\mathrm{C})$. This peak can be explained by a presence of a thin hydroxide layer on the carbon steel surface, i.e. OH-Fe. This decomposition could be completed by the fourth component, at higher binding energy, to reconstitute the experimental spectrum. However, we decided only to play on the ratio of $\mathrm{G} / \mathrm{L}$ for the last component. The full width at half maximum (FWHM) value of 
different carbon peak components was considered to be $1.56 \mathrm{eV}$. Compared to the FWHM of $0.8 \mathrm{eV}$ for $\mathrm{C} 1 \mathrm{~s}$ recorded from the HOPG (Highly Oriented Pirolitic Graphite) reference sample, the width increase demonstrated complex and heterogeneous sample surfaces. After the conditioning at different biosurfactants concentrations (BS-1 sample is presented in Figure $\mathbf{6}(\mathbf{b})$ ), the total carbon increases $(+20 \%)$, and we observed the same three components with significant contribution. Indeed, the first peak at $285.0 \mathrm{eV}$ is slightly decreased $(\approx 0.6 \%)$, which may be explained by the appearance of aromatic bonds [40]. The second and third components at $286.6 \mathrm{eV}$ and $288.2 \mathrm{eV}$ increase significantly and can be ascribed to involving new bonds between carbon and nitrogen or oxygen atoms in C-N and C-OH bonds. The peak at $288.2 \mathrm{eV}$ is sometimes attributed to compounds such as ester, acetate, amide, carbonyl and carboxylate compounds, which are in good accordance with the biosurfactant's structure. The complementary peak that appears at $289.7 \mathrm{eV}$ can be ascribed to the creation of the double carbon bonds to oxygen and nitrogen.

\subsubsection{Analysis of $O 1 \mathrm{~s}$ spectra}

The O 1s core level spectra for all samples clearly show two components. The asymmetry of spectra at higher binding energies expects two and three component-shoulders for the Blank and biosurfactants samples, respectively at (Figure $7(\mathbf{a}, \mathbf{b}))$.

By taking as example Blank and BS-1 samples, the peaks were fitted as follows:

- The first peak at $529.8 \mathrm{eV} / 529.9 \mathrm{eV}$ is attributed to $\mathrm{O}^{2-}$, which represents the lattice oxygen [40]. It could though be attributed to oxygen atoms bonded with iron in the $\mathrm{Fe}_{2} \mathrm{O}_{3}$ and $\mathrm{Fe}_{3} \mathrm{O}_{4}[\mathbf{4 1}, \mathbf{4 2}$. The two fold decrease in integrated intensity from Blank to biosurfactant samples is due to the creation of the biosurfactant layer on the carbon steel (as was deduced from survey scans data for the Fe $2 p$ signal). 
- The second peak observed at $531.5 \mathrm{eV} / 531.6 \mathrm{eV}$ is probably related to $\mathrm{OH}^{-}$and can be associated with the presence of a hydroxide layer on the steel surface, such as $\mathrm{FeOOH}$ and/or $\mathrm{Fe}(\mathrm{OH})_{3}$ [43]. Secondly, amide and carboxyl compounds were also reported at $531.3 \pm 0.3 \mathrm{eV}$ [44];

- The third component at $532.9 \mathrm{eV} / 534.4 \mathrm{eV}$ relates to oxygen from the chemically or physically adsorbed water, or to oxygen making a single bond with carbon [45]. Indeed, the nature of this peak is difficult to explain, because it is not due to the presence of carboxyl, acetal or hemiacetal groups, but is properly associated to the carbonyl groups that come from the contamination;

- Finally, the peak at $534.2 \mathrm{eV} / 534.4 \mathrm{eV}$ can be related to the presence of nitrogen-oxygen double bonds.

- The complementary peak at $536.0 \mathrm{eV}$, which was always seen in BS samples, may indicate the presence of compounds containing $\mathrm{C}-\mathrm{NO}_{2}$ groups. 


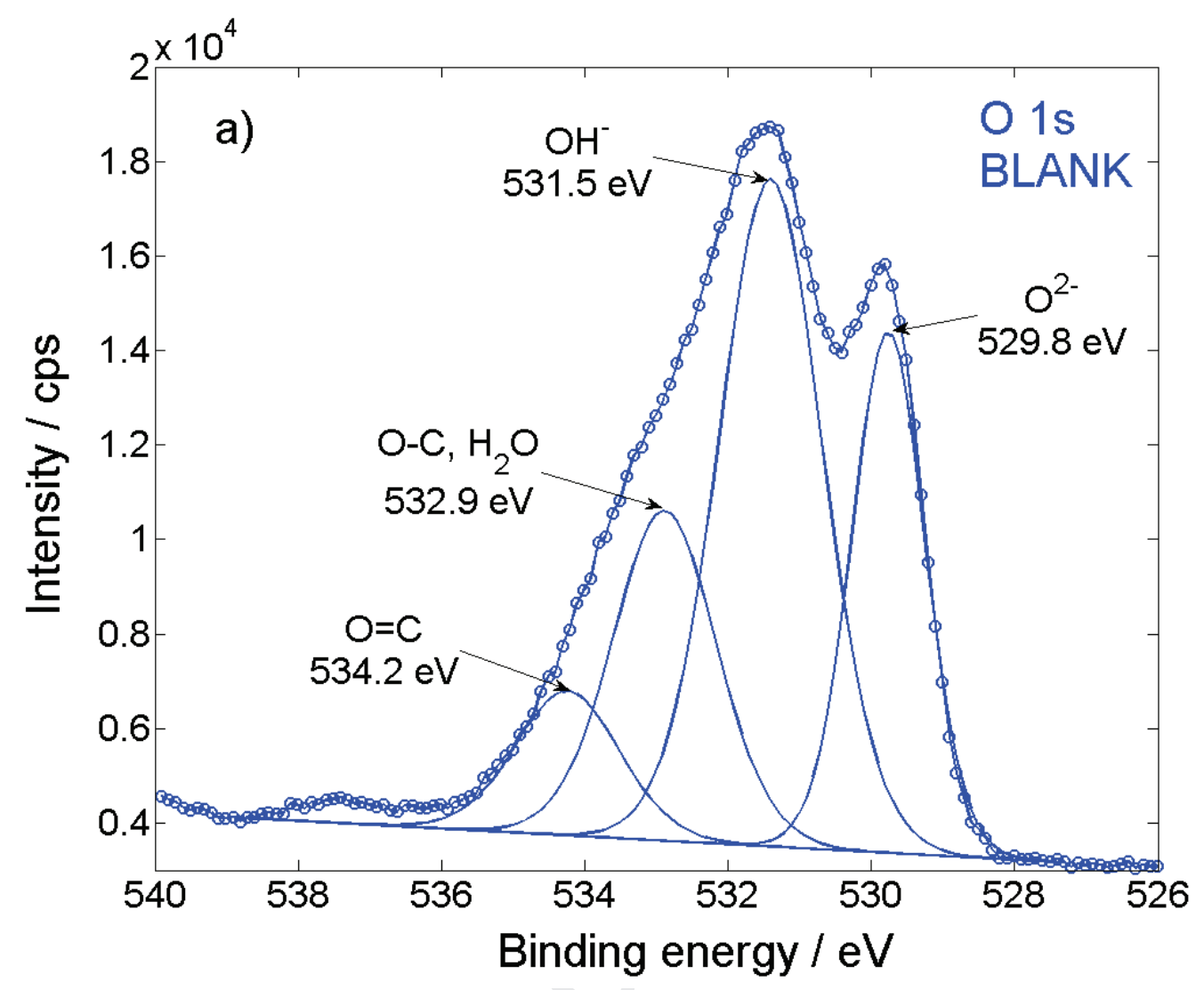




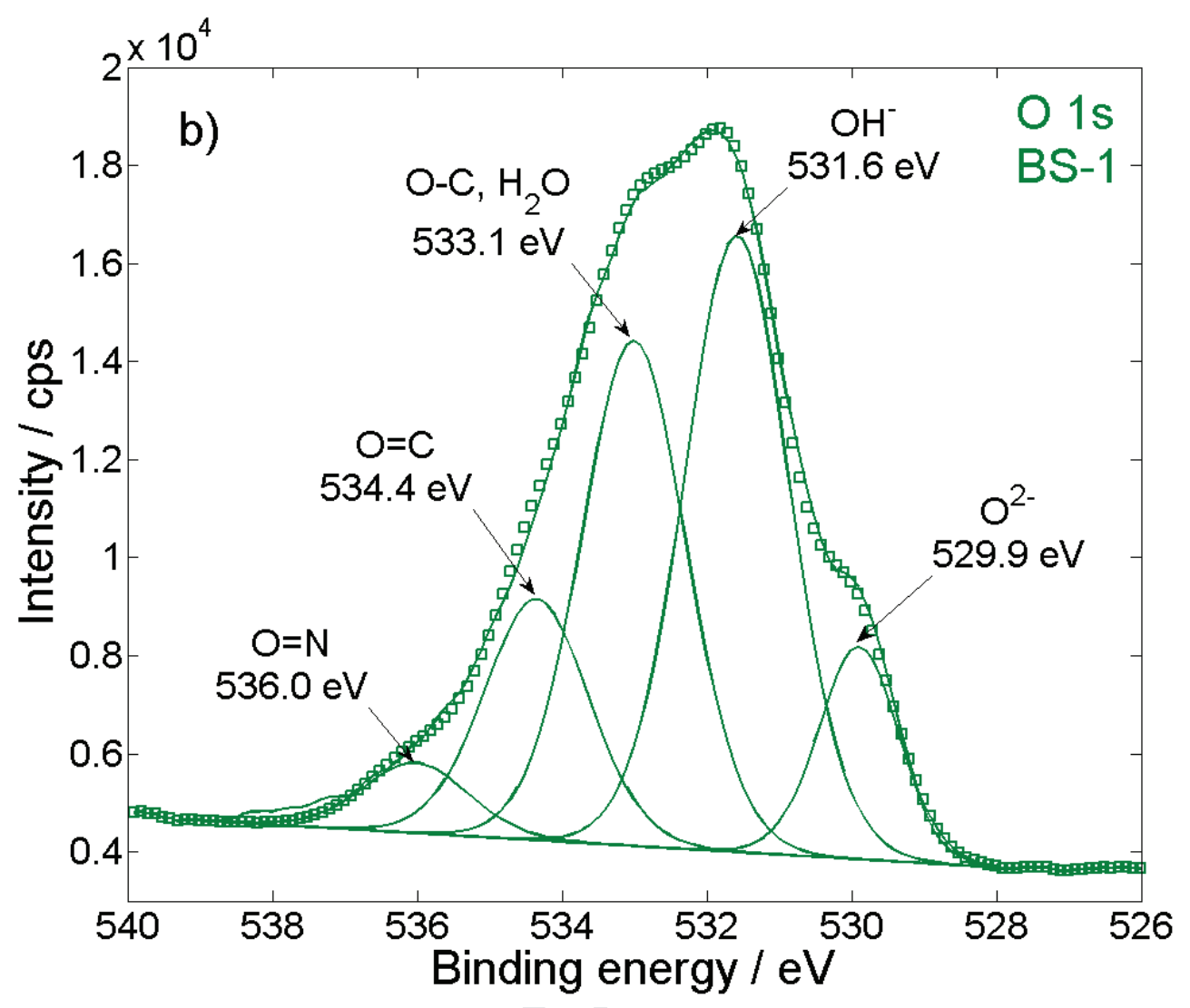

Figure 7. O 1s high resolution XPS spectra obtained for Blank (a) and BS-1 samples (b).

\subsubsection{Analysis of $\mathrm{N} 1 \mathrm{~s}$ spectra}

For the Blank sample, the nitrogen signal is low (Figure 8 (a)) (less than 5\% of the $\mathrm{N}$ 1s intensity for all the samples that were conditioned in different BS concentrations) and centred at $400.5 \pm 0.1 \mathrm{eV}$, so it is probably due to organic contaminants present in water [46]. 


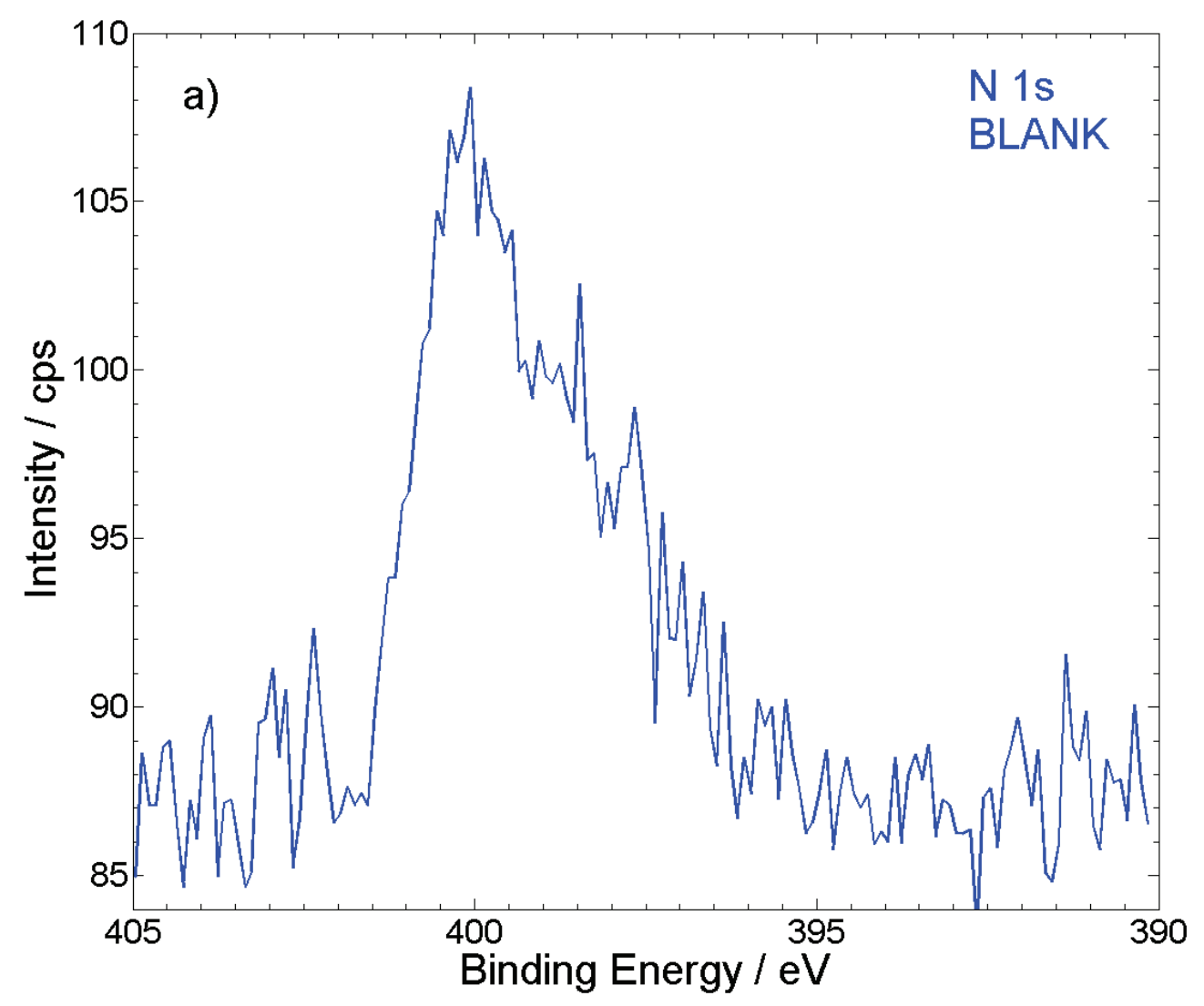






Figure 8. N 1s high resolution XPS spectra obtained for Blank (a) and BS-1 samples (b).

The N 1s spectra envelopes for all the biosurfactant-conditioned samples were fitted using two components with FWHM $=1.7 \mathrm{eV}$ and $\mathrm{G} / \mathrm{L}=30$, as shown in Figure 8 (b). The first peak at $400.2 \mathrm{eV}$ has the highest contribution and is mainly attributed to nitrogen atoms characteristic of non-protonated nitrogen, $\mathrm{N}-\mathrm{CH}$. This component (FWHM $\sim 1.6 \mathrm{eV}$ ) is typical for amides and amines in the ring [47]; or a nitrogen atom coordinated with the steel surface $(\mathrm{N}-\mathrm{Fe})$ [39]. The second $\mathrm{N} \mathrm{1s}$ component at $402.4 \mathrm{eV}$ indicates a new bond involving nitrogen groups attributed to positively charged nitrogen [45]. The presence of protonated nitrogen can be explained by hydrogen bonding between one hydrogen atom 
bonded to a nitrogen atom of the amino group and the electron lone pair of a nitrogen atom of another biosurfactants molecule.

XPS results for BS- 0.05 , BS- 0.3 and BS- 1 show that the atomic concentration of N1s peaks increase with BS concentration, as we can see in Table A-3 of Appendix.

\subsubsection{Analysis of Fe 2p spectra and BS layer thickness determination}

Iron spectra composed of a doublet structure due to spin-orbit splitting ( $\mathrm{Fe} 2 \mathrm{p}_{3 / 2}$ and $\mathrm{Fe} 2 \mathrm{p}_{1 / 2}$ ) as shown by the spectrum in Figure 9. Both $\mathrm{Fe} 2 \mathrm{p}_{3 / 2}$ and $\mathrm{Fe} 2 \mathrm{p}_{1 / 2}$ are large, with a shoulder at the high binding energy side, suggesting that there are at least two unresolved contributions for the iron signal. In order to investigate the composition of surface film on iron the binding energies of different iron compounds reported in literature were compiled and average values were chosen as fitting parameters. We decided to envelope Fe 2p spectra for all surfaces with two main components and an additional component associated with shake-up [48]. The full width at half maximum (FHWM) values of different iron-containing compounds were established as constant for all samples $\left(2.5 \mathrm{eV}\right.$ for $\mathrm{Fe}^{3+}$ and $3.0 \mathrm{eV}$ for $\mathrm{Fe}^{2+}$ ) except BS-0. The illustration of fitting results for the Blank sample is presented in Figure 9. After biosurfactant adsorption, the outer surface $\mathrm{Fe}^{3+}$-rich layer associated with magnetite was investigated. This indicated that biosurfactant adsorption changes the stoichiometry of outer oxide layer composition. 


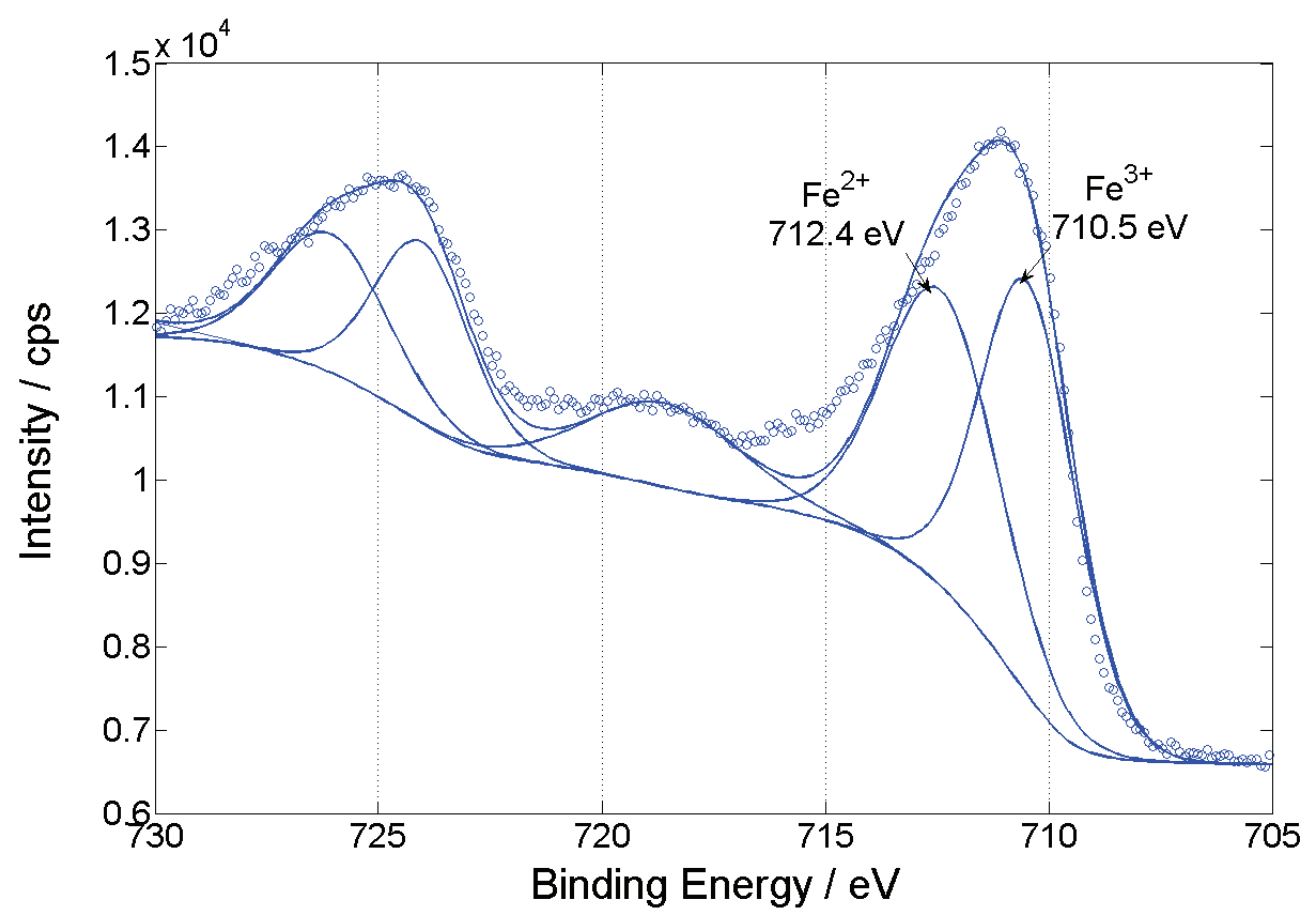

Figure 9. An example of curve fitting for a Fe $2 p$ high resolution spectrum for the Blank sample.

The Fe $2 p$ spectra of five specimens (i.e. Blank, BS- 0 , BS- 0.05 , BS- 0.3 and BS1) are compared in Figure $\mathbf{1 0}$ and can be used to qualitatively compare the film thickness of adsorbed biosurfactant. It is clear that conditioning in biosurfactant solutions reduces the intensities of iron peaks. Since iron peaks are recorded under the same experimental parameters, the intensity of Fe $2 p$ peaks can be used as an indicator to estimate the thickness of the biosurfactants layer. Assuming that (i) the thickness of the oxide film on the Blank sample (which was not subjected to any treatment) will be used as a reference point, and that (ii) we obtained a uniform layer of biosurfactants on the steel surface (Figure 11), a semi-quantitative approach can be used. 


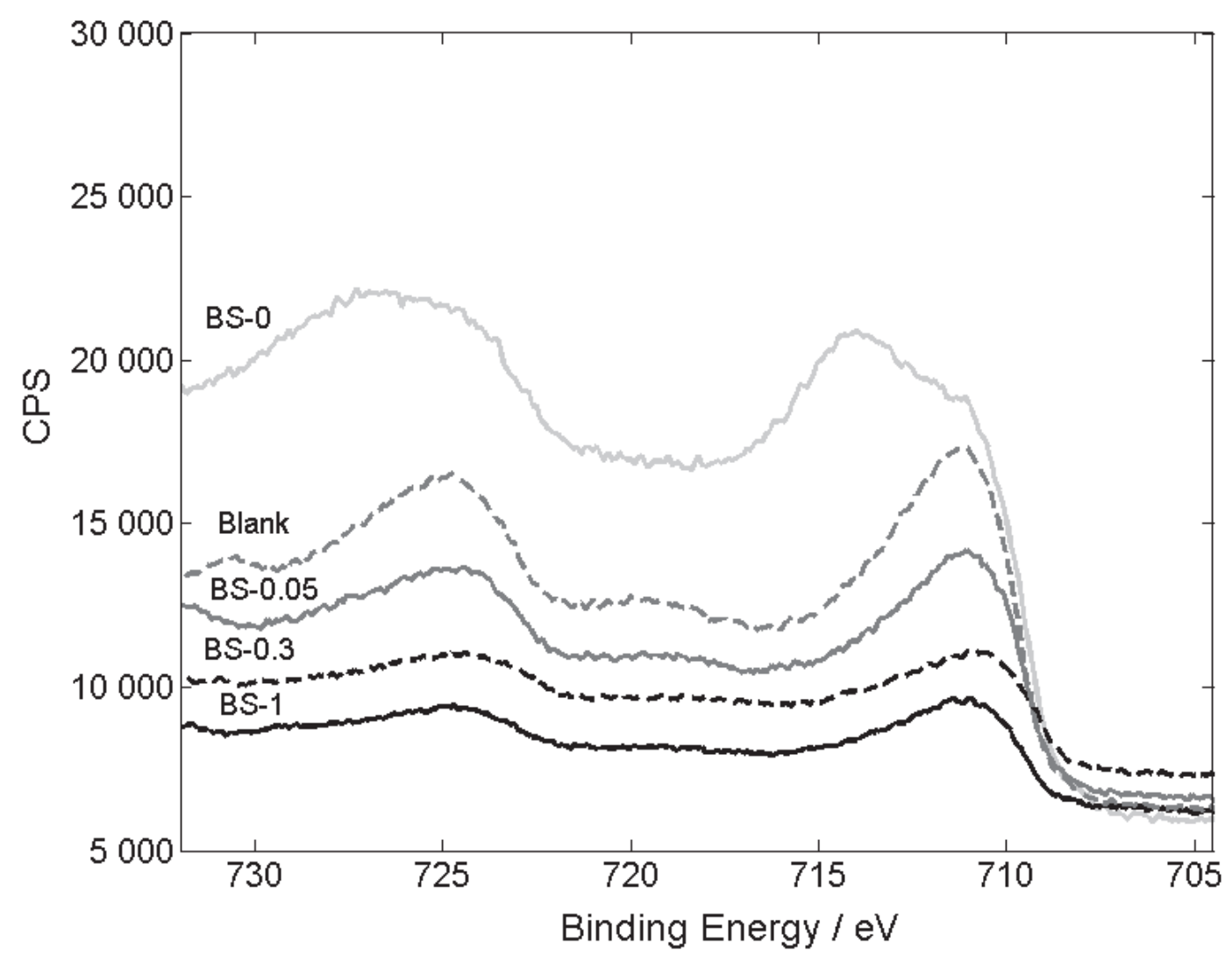

Figure 10. Evolution of intensity (cps) for the Fe $2 p$ high resolution XPS spectra obtained from Blank, BS-0, BS-0.05, BS-0.3, BS-1 carbon steel specimens.

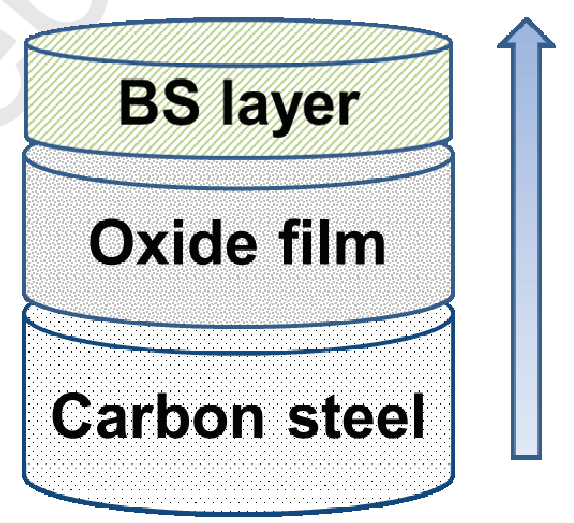

Figure 11. Model of carbon steel surface with biosurfactant layer.

Accordingly, the biosurfactant layer thickness can be calculated from the intensity ratios, as: 


$$
d_{B S}=\lambda_{F e}^{B S-X} \cdot \ln \left(\frac{I_{\text {blank }}^{F e}}{I_{B S-X}^{F e}}\right),
$$

where $\mathrm{d}_{\mathrm{BS}}$ is the thickness of the biosurfactant layer, $\mathrm{I}_{\text {blank }}^{\mathrm{Fe}}$ and $\mathrm{I}_{\mathrm{BS}-\mathrm{X}}^{\mathrm{Fe}}$ are the integrated intensities of the Fe $2 \mathrm{p}_{3 / 2}$ iron component for Blank and BS-X ( $X=$ $0.05,0.3,1)$ samples, respectively, obtained from Fe $2 \mathrm{p}$ spectra and $\lambda_{\mathrm{Fe}}^{B S-X}$ is a IMFP (Inelastic Mean Free Path) for Fe 2p, taken here as $24 \AA$ [49].

The calculated average biosurfactant layer thickness for BS-0.05, BS-0.3 and BS- 1 are $7.9 \pm 0.3,12.1 \pm 0.5$ and $16.4 \pm 0.7 \AA$, respectively. From these estimations, we can consider that the adsorption of biosurfactant molecules takes place for all the conditioning samples (i.e. BS-X). In addition, the results suggest that the average thickness of biosurfactant layer slightly increases with increasing BS concentration. These average layer thicknesses cannot be accurate values, because many parameters have not been taken into account. However, it can give us an idea about the organization of layers. It is logical that the values $12.1 \pm 0.5$ and $16.4 \pm 0.7 \AA$ are close to each other, because the biosurfactant solution concentrations 0.3 g.L $\mathrm{L}^{-1}$ and 1 g. $\mathrm{L}^{-1}$ are close to threshold point of the critical micelle concentration (CMC) and in the CMC zone, respectively. On the other hand, we can see that insufficient biomolecules concentration $\left(0.05\right.$ g.L $\left.\mathrm{L}^{-1}\right)$ could create a layer with about $7.9 \pm 0.3 \AA$ thick.

To estimate the biosurfactant layer on the surface in another way, we supposed that for the low biosurfactant concentration, the molecules are tilted and lie closer to the surface. When the biosurfactant concentration increases, the molecules of biosurfactant "stand up" on the surface. Assuming that N 1s signal indicates the presence of the biosurfactant (i) and that (ii) the biosurfactant molecules are distributed uniformly on the surface, we attempted to take into account the $\mathrm{N}$ 1s core level to find layer density. Using the relation of $\mathrm{I}^{\mathrm{N} 1 \mathrm{~s}}{ }_{\mathrm{BS}}$ (intensity signal of N 1s on biosurfactant conditioned surface (see Table A-3 of 
Appendix) and $\mathrm{d}^{\mathrm{Fe}}{ }_{\mathrm{BS}-\mathrm{X}}$ the carbon steel surface, and comparing with reference (HOPG, $\mathrm{N}_{\mathrm{s}}=4 \times 10^{15}$ atomes $/ \mathrm{cm}^{2}$ ), the signal of $\mathrm{N}$ 1s core level sample is equivalent to $5 \times 10^{14}, 3 \times 10^{14}$ and $1 \times 10^{14}$ atoms $/ \mathrm{cm}^{2}$ for BS-1, BS-0.3 and BS0.05 samples respectively. These quantitative results suggest that the density of the biosurfactant layer on the surface increases with increasing biosurfactant concentration. It must be underlined once again, that the heterogeneity of the layer has not been taken into account; therefore this information is valid only in the case of a homogenous ad-layer. This result is consistent with that of iron: when biosurfactant concentration increases, the biosurfactant layer thickness increases and the number of molecules on the surface increases. These molecules then will have to "stand up" (more compact layer) on the surface instead of "lie down" at low concentrations.

The more compact layer was also specified using contact angle measurement results. The significant increase in surface energy due to an increased polar component is due to creation of a compact biosurfactant layer by anchoring $\mathrm{NH}_{2}$ functional groups on the metal surface. Consequently, the lipid part of biosurfactant molecules is turned outwards from the surface. These lipids, which are presumably hydrophobic, have an important property, reported by Boggs $[50,51]$.That is their ability to create a network of intermolecular hydrogen bonds to increase the packing density in the biosurfactant layer, and increase the polar component of the surface energy.

\section{CONCLUSIONS}

Modification of carbon steel using three concentrations: $0.05,0.3$ and $1 \mathrm{~g} . \mathrm{L}^{-1}$ of biosurfactants derived from Pseudomonas fluorescens was studied using CAM and XPS measurements. From this study, we can draw the following conclusions: 
- Adsorption of the biosurfactant increases the polar component of the surface energy due to a compact layer being created as $-\mathrm{NH}_{2}$ functional groups are anchored on a metal surface;

- The significant surface changes were investigated from XPS study of C 1s, O 1s, N 1s and Fe 2p peaks. The biosurfactant adsorption changes the stoichiometry of the surface's outer layer; the intensity of the component associated with magnetite increases.

- The N 1s core level was specified as a signature of biosurfactant adsorption. The $\mathrm{N} 1 \mathrm{~s}$ core level signal is equivalent to $5 \times 10^{14}, 3 \times 10^{14}$ and $1 \times 10^{14}$ atoms $/ \mathrm{cm}^{2}$ for samples BS-1, BS- 0.3 and BS- 0.05 respectively.

- Assuming a homogenous ad-layer, the thickness of the biosurfactant layer was found to be approximately $7.9 \pm 0.3,12.1 \pm 0.5$ and $16.4 \pm 0.7 \AA$, for $0.05,0.3$ and 1 g. $\mathrm{L}^{-1}$ of biomolecules, respectively.

In this work, the conditioning of steel coupons in deionized water leads to the formation of a uniform film of adsorbed molecules on the steel surface. The properties of this film are strongly dependent on the concentration of the BS. The thickness of the adsorbed films slightly increases with the BS concentration up to a threshold value corresponding to a specific arrangement of molecules on the surface that could be also related to the modification of the composition of the iron oxide film in presence of BS molecules. This finding can explain our first positive results concerning corrosion prevention by using biomolecules but further research using electrochemical methods must be done to confirm these results. In addition, the ellipsometry technique can be applied to support our experimental results of adsorbed biosurfactant thickness values deduced from XPS analysis.

\section{APPENDIX}


Table A-1. Contact angle measurements of carbon steel samples after immersion at different biomolecule concentrations.

\begin{tabular}{|l|c|c|c|c|}
\hline \multirow{2}{*}{ Samples } & \multicolumn{3}{|c|}{ Contact angles, } \\
\cline { 2 - 5 } & diiodomethane & ethylene glycol & glycerol & water \\
\hline Blank & $43.3 \pm 2.9$ & $51.3 \pm 1.2$ & $33.8 \pm 2.5$ & $76.7 \pm 1.2$ \\
\hline BS-0.05 & $58.4 \pm 1.8$ & $12.4 \pm 1.0$ & $36.3 \pm 1.3$ & $28.9 \pm 0.45$ \\
\hline BS-0.3 & $61.8 \pm 2.1$ & $11.8 \pm 0.8$ & $38.5 \pm 2.2$ & $0 *$ \\
\hline BS-1 & $60.7 \pm 1.6$ & $10.7 \pm 0.9$ & $36.7 \pm 1.8$ & $0 *$ \\
\hline
\end{tabular}

Table A-2. Surface tension and components for testing liquids (at $20^{\circ} \mathrm{C}$ ) [30].

\begin{tabular}{|c|c|c|c|}
\hline Liquid & $\sigma_{L}, \mathbf{m N} / \mathbf{m}$ & $\sigma_{L}^{D}, \mathbf{m N} / \mathbf{m}$ & $\sigma_{L}^{P}, \mathbf{m N} / \mathbf{m}$ \\
\hline Water (W) & 72.8 & 21.8 & 51.0 \\
\hline Diiodomethane (D) & 50.8 & 50.8 & 0 \\
\hline Ethylene glycol (E) & 48.0 & 29.0 & 19.0 \\
\hline Glycerol (G) & 64.0 & 34.0 & 30.0 \\
\hline
\end{tabular}


Table A-3. XPS elements concentration (at.\%) of the surface films for Blank, BS-0.05, BS-0.3 and BS-1 samples.

\begin{tabular}{|c|c|c|c|c|}
\hline & Fe, at.\% & O, at.\% & C, at\% & N, at.\% \\
\hline Blank & $19.1 \pm 2.5$ & $21.1 \pm 2.5$ & $59.8 \pm 1.5$ & $0.12 \pm 0.1$ \\
\hline BS-0.05 & $3.5 \pm 0.8$ & $48.6 \pm 1.5$ & $42.8 \pm 1.4$ & $2.9 \pm 0.5$ \\
\hline BS-0.3 & $1.1 \pm 0.5$ & $33.0 \pm 1.8$ & $57.1 \pm 2.3$ & $5.3 \pm 0.7$ \\
\hline BS-1 & $0.5 \pm 0.5$ & $32.6 \pm 1.7$ & $57.3 \pm 1.5$ & $9.7 \pm 1.5$ \\
\hline
\end{tabular}

\section{ACKNOWLEDGMENTS}

The authors are thankful to Sophie Ricordel, Michel Grasset and Jonathan Hamon for technical assistance and to Thomas Le Noir for advice on preparing this manuscript.

\section{REFERENCES}

[1] L. Fracchia, M. Cavallo, M.G. Martinotti, I.M. Banat, Biosurfactants and bioemulsifiers biomedical and related applications - Present status and future potentials, Biomedical Science, Engineering and Technology, Prof. D.N. Ghista, InTech, 2012.

[2] C. N. Mulligan, Environmental applications for biosurfactants, Environ. Pollut. 133(2) (2005) 183-198.

[3] I.M. Banat, A. Franzetti, I. Gandolfi, G. Bestetti, M.G. Martinotti, L. Fracchia, T.J. Smyth, R. Marchant, Microbial biosurfactants production, applications and future potential. Appl. Microbiol. Biotechnol. 87(2) (2010) 427-444.

[4] J. D. Desai, I. M. Banat, Microbial production of surfactants and their commercial potential. Microbiol. Molec. Reviews. 61 (1997), 47-64.

[5] E.M. Ciapina ,W.C. Melo, L.M. Santa Anna, A.S. Santos, D.M. Freire, N.Jr. Pereira, Biosurfactant production by Rhodococcus erythropolis grown on glycerol as sole carbon source, Appl. Biochem. Biotechnol. 131 (2006) 1-3. 
[6] L. Guerra-Santos, O. Käppeli, A Fiechter, Pseudomonas aeruginosa biosurfactant production in continuous culture with glucose as carbon source. Appl. and Environ. Microbiol. 48 (1984) 301-305.

[7] D.G. Cooper, J.E. Zajic, D.F. Gerson, Production of surface-active lipids by Corynebacterium lepus, Appl. Environ. Microbiol. 37(1) (1979) 4-10.

[8] C.R. MacDonald, D.C. Cooper, J.E. Zajic, Surface-active lipids from Nocardia erythropolis grown on hydrocarbons. Appl. Environ. Microbiol. 41(1) (1981) 117- 123.

[9] Z. Zhao, J.W. Wong, Biosurfactants from Acinetobacter calcoaceticus BU03 enhance the solubility and biodegradation of phenanthrene, Environ. Technol. 30(3) (2009) 291.

[10] D.G. Cooper, C.R. Macdonald, S.J.B. Duff, N. Kosaric, Enhanced Production of Surfactin from Bacillus subtilis by Continuous Product Removal and Metal Cation Additions, Appl. Environ. Microbiol. 42(3) (1981) 408-412.

[11] T.H. Nielsen, J. Sørensen, Production of cyclic lipopeptides by Pseudomonas fluorescens strains in bulk soil and in the sugar beet rhizosphere, Appl. Environ. Microbiol. 69(2) (2003) 861-868.

[12] T. Matsuyama, K. Kaneda, Y. Nakagawa, K. Isa, H. Hara-Hotta, I. Yano, A novel extracellular cyclic lipopeptide which promotes flagellumdependent and -independent spreading growth of Serratia marcescens. J. Bacteriol. 174(6) (1992) 1769-1776.

[13] S.M. Mandal, A.E. Barbosa, O.L. Franc, Lipopeptides in microbial infection control: Scope and reality for industry. Biotechnol. Adv. 31 (2013) 338-345.

[14] E. Rosenberg, E. Ron, High- and low-molecular-mass microbial surfactants. Appl. Microbiol. Biotechnol. 52(2) (1999) 154-62.

[15] T. Meylheuc, C.J. van Oss, M.-N. Bellon-Fontaine,. Adsorption of biosurfactant on solid surfaces and consequences regarding the bioadhesion of Listeria monocytogenes LO28, J. Appl. Microbiol. 91 (2001) 822-832.

[16] T. Meylheuc, C. Methivier, M. Renault, J-M. Herry, C.-M. Pradier, M. N. Bellon-Fontaine, Adsorption on stainless steel surfaces of biosurfactants produced by gram-negative and gram-positive bacteria: Consequence on the bioadhesive behavior of Listeria monocytogenes, Colloids Surf. B. 52 (2) (2006) 128-137.

[17] C. Dagbert, T. Meylheuc, M. N. Bellon-Fontaine, Corrosion behaviour of AISI 304 stainless steel in presence of a biosurfactant produced by Pseudomonas fluorescens, Electrochim. Acta 51 (24) (2006) 5221-5227. 
[18] C. Dagbert, T. Meylheuc, M. N. Bellon-Fontaine, Pit formation on stainless steel surfaces pre-treated with biosurfactants produced by Pseudomonas fluorescens, Electrochim. Acta 54 (1) (2008) 35-40.

[19] V. Shubina, L. Gaillet, T. Chaussadent, Utilisation des biosurfactants comme «biorevêtement» anticorrosion sur armatures béton armé, Journées Techniques Ouvrages d'Art 2014, 11 - 13 juin 2014, Ecole Nationale des Ponts et Chaussées, Paris, France. (http://actionsincitatives.ifsttar.fr/fileadmin/uploads/recherches/seminaires/JOA2014/J118 ER3-1_V-SHUBINA.pdf)

[20] V. Shubina, L. Gaillet, T. Chaussadent, S. Ricordel, V. Gaudefroy, J. Creus, Biosurfactant coatings as innovative inhibitors against corrosion of steel rebars, EUROCOAT 2014, 23-25 septembre 2014, Versailles, France. (http://www.eurocoat-expo.com/biosurfactant-coatings-asinnovative-inhibitors, 227)

[21] V. Shubina, L. Gaillet, T. Chaussadent, T. Meylheuc, J. Creus, Biomolecules as a sustainable protection against corrosion of reinforced carbon steel in concrete, ERSCP 2014 Conference, 14-16 October 2014, Portorož,Slovenia.(https://conferences.matheo.si/contributionDisplay.py? contribId $=130 \&$ confId $=0$ )

[22] A.F. de Faria, D.S. Teodoro-Martinez, G.N. de Oliveira Barbosa, B.G. Vaz, Í.S. Silva, J.S. Garcia, M.R. Tótola, M.N. Eberlin, M. Grossman, O.L. Alves, L.R. Durrant, Production and structural characterization of surfactin (C14/Leu7) produced by Bacillus subtilis isolate LSFM-05 grown on raw glycerol from the biodiesel industry, Process Biochem. 46 (10) (2011) 1951-1957.

[23] G.F. Mohamed, M.S. Shaheen Safaa, K.H Khalil, M.S. Hussein Ahmed, M. Kamil Mohie, Application of FT-IR Spectroscopy for Rapid and Simultaneous Quality Determination of Some Fruit Products, Nat. Sci. 9 (2011) 21-31.

[24] G. Ferré, F. Besson, R. Buchet, Conformational studies of the cyclic 1, d-lipopeptide surfactin by Fourier transform infrared spectroscopy, Spectrochim. Acta Part A, 53 (4) (1997) 623-635.

[25] B.R. Singh, S. Dwivedi, A.A. Al-Khedhairy, J. Musarrat, Synthesis of stable cadmium sulfide nanoparticles using surfactin produced by Bacillus amyloliquifaciens strain KSU-109, Colloids Surf. B., 85 (2: 1) (2011) 207-213.

[26] M. Soledade, C. Pedras, N. Ismail, J.W. Quail, S.M. Boyetchko, Structure, chemistry, and biological activity of pseudophomins A and B, new cyclic lipodepsipeptides isolated from the biocontrol bacterium Pseudomonas fluorescens, Phytochem., 62 (2003) 1105-1114. 
[27] S. Lang, F. Wagner, Structure and properties of biosurfactants in: N. Kosaric, W.L. Cairns, N.C.C. Gray (Eds.), Biosurfactants and Biotechnology, Marcel Dekker, New York, 1981.

[28] T. Janek, M. Łukaszewicz, T. Rezanka, A. Krasowska, Isolation and characterization of two new lipopeptide biosurfactants produced by Pseudomonas fluorescens BD5 isolated from water from the Arctic Archipelago of Svalbard, Bioresour. Technol., 101 (2010) 6118-6123.

[29] Y. Yuan, T.R. Lee, Contact Angle and Wetting Properties, Surface Science Techniques, in: G. Bracco, B. Holst (eds), Springer Series in Surface Sciences 51, UK, 2013.

[30] J. B. Rosenholm, The Role of Surface Forces, Part II: Colloids and Interface Science, in: Colloid Stability vol. 2, T.F. Tadros (eds), WileyVCH Verlag Gmbh Co, Germany, 2007.

[31] M. Motamedi, A.R. Tehrani-Bagha, M. Mahdavian, Effect of aging time on corrosion inhibition of cationic surfactant on mild steel in sulfamic acid cleaning solution, Corr. Sci., 2013, vol. 70, pp. 46-54.

[32] C. Rulison, Technical note \#306, http://www.kruss.de, KRÜSS, USA.(https://cmi.epfl.ch/metrology/files/Kruss-DSA30/kruss-tn306en.pdf)

[33] L.R. Rodrigues, I.M. Banat, H.C. van der Mei, J.A. Teixeira, R. Oliveira, Interference in adhesion of bacteria and yeasts isolated from explanted voice prostheses to silicone rubber by rhamnolipid biosurfactants, J. Appl. Microbiol., 100 (2005) 470-480.

[34] C.J. van Oss, M.K. Chaudhury, R.J. Good, Interfacial Lifshitz-van der Waals and Polar Interactions in Macroscopic Systems, Chem. Rev., 88 (1988) 927-941.

[35] A.E. Zeraik, M. Nitschke, Biosurfactants as agents to reduce adhesion of pathogenic bacteria to polystyrene surfaces: effect of temperature and hydrophobicity, Cur. Microbiol., 61(6) (2010) 554-559.

[36] A. Vallée, V. Humblot, R.A. Housseiny, S. Boujday, C-M. Pradier, BSA adsorption on aliphatic and aromatic acid SAMs: Investifating the effect of residual surface charge and sublayer nature, Colloids Surf. B. 109 (2013) 136-142.

[37] S.A. Lawrence, Amines: Synthesis, Properties and Applications, Cambridge University Press, UK, 2004.

[38] A.J. Swift, Surface analysis of corrosion inhibitor films by XPS and ToF-SIMS, Mikrochim. Acta 120 (1995), 149-158.

[39] O. Olivares-Xometl, N.V. Likhanova, R. Martinez-Palou, M.A. Dominguez-Aguilar, Electrochemistry and XPS study of an imidazoline as corrosion inhibitor of mild steel in an acidic environment, Mater. Corros. 60 (1) (2009) 14-21. 
[40] M. Outirite, M. Lagrenée, M. Lebrini, M. Traisnel, C. Jama, H. Vezin, F. Bentiss, ac impedance, X-ray photoelectron spectroscopy and density functional theory studies of 3,5-bis(n-pyridyl)-1,2,4-oxadiazoles as efficient corrosion inhibitors for carbon steel surface in hydrochloric acid solution, Electrochim. Acta 55 (5) (2010) 1670-1681.

[41] A. Alagta, I. Felhösi, I. Bertoti, E. Kálmán, Corrosion protection properties of hydroxamic acid self-assembled monolayer on carbon steel, Corros. Sci. 50 (6) (2008) 1644-1649.

[42] M. Tourabi, K. Nohair, M. Traisnel, C. Jama, F. Bentiss, Electrochemical and XPS studies of the corrosion inhibition of carbon steel in hydrochloric acid pickling solutions by 3,5-bis(2-thienylmethyl)4-amino-1,2,4-triazole, Corros. Sci. 75 (2013) 123-133.

[43] J. Cruz, R. Martínez, J. Genesca, E. Garcia-Ochoa, Experimental and theoretical study of 1-(2-ethylamino)-2-methylimidazoline as an inhibitor of carbon steel corrosion in acid media, J. Electroanal. Chem. 566 (1) (2004) 111-121.

[44] P. Shakeri Fard, Production and purification of biosurfactants and study of their influence on surface properties of stainless steel and Teflon, Effect of different Bacillus subtilis lipopeptides on surface hydrophobicity and adhesion of Bacillus cereus 98/4 spores to stainless steel and teflon, Ph.D. Thesis, Université de Lille1: Sciences et Technologies, France, 2010.

[45] G.Gunasekaran, L.R. Chauhan, Eco friendly inhibitor for corrosion inhibition of mild steel in phosphoric acid medium, Electrochim. Acta 49 (25) (2004) 4387-4395.

[46] L. Lartundo-Rojas, Influence de l'adsorption de protéine (BSA) sur le comportement électrochimique et la composition de surface d'un alliage Fe-17Cr en solution aqueuse, Ph.D. Thesis, University of Paris VI, France, 2007.

[47] M. Chevalier, F. Robert, N. Amusant, M. Traisnel, C. Roos, M. Lebrini, Enhanced corrosion resistance of mild steel in $1 \mathrm{M}$ hydrochloric acid solution by alkaloids extract from Aniba rosaeodora plant: Electrochemical, phytochemical and XPS studies, Electrochim. Acta 131 (2014) 96-105.

[48] P. Ghods, O. Burkan Isgor, F. Bensebaa, D. Kingston, AngleResolved XPS study of carbon steel passivity and chloride-induced depassivation in simulated concrete pore solution, Corros. Sci. 58 (2012) 159-167.

[49] C.J. Powell and A. Jablonski, NIST Electron Inelastic-Mean-FreePath-Database, Version 1.2, SRD 71, National Institute of Standards and Technology, Gaithersburg, MD, 2010. 
[50] J.M. Boggs, Effect of lipid structural modifications on their intermolecular hydrogen bonding interactions and membrane functions, Biochem. Cell. Biol. 64 (1986) 50.

[51] J.M. Boggs, Lipid intermolecular hydrogen bonding: influence on structural organization and membrane function, Biochim. Biophys. Acta 906 (1987) 353-404. 